\title{
VII. On certain defects in the British Almanac
}

\section{B. Bevan Esq.}

To cite this article: B. Bevan Esq. (1833) VII. On certain defects in the British Almanac, Philosophical Magazine Series 3, 2:7, 30-32, DOI: 10.1080/14786443308647960

To link to this article: http://dx.doi.org/10.1080/14786443308647960

册 Published online: 01 Jun 2009.

Submit your article to this journal 준

Џ Article views: 2

Q View related articles $₫$ 
nomena observed by me are entirely inconsistent with this supposition. If homogeneous light were used, then (on this supposition) the bright-centred rings would disappear and black-centred rings would succeed them as at the polarizing angle of the glass. If white light were used, the rings in the neighbourhood of the polarizing angle would be wholly coloured, and on changing the angle the intensity of the different colours in each ring would alter, but there would be nothing like contraction. Thus at a certain angle the brightest part of the red would be at the centre of the spot, and its faintest part would be in the first ring; while for the blue the places would be reversed: on increasing the angle the brightest parts of both would be in the first ring. Whereas in my experiments there was no discoverable alteration in the colours of the rings, there never was seen a bright red centre surrounded by a bright blue ring; but the rings, without changing their character as to colour, diminished steadily till the central spot was as it were squeezed out. Whether the only diamond which I have used may possess any peculiarity which distinguishes it from those used by Sir David Brewster, I cannot say. Meantime I may observe, that the singularity in the reflexion at the surface of the diamond makes it not improbable that there may be some singularity in the refraction also, and renders a more extended inquiry into the laws both of its reflexion and of its refraction highly desirable.

Observatory, Feb. 16, 1832.

G. B. Airy.

VII. On certain Defects in the British Almanac. By B. Bevan, Esq.

\section{To the Editors of the Philosophical Magazine and Journal.} Gentlemen,

IS it not worthy of remark, that an Almanac published under the patronage of so learned a Society as that established for the Diffusion of Useful Knowledge, should continue to be published without giving the sun's declination? It cannot surely be owing to a want of room, when two pages per month are appropriated to the calendar.

The patrons of this publication must be aware of the importance of this information to all persons who may wish to become acquainted with practical astronomy. The declination of the sun is independent of the latitude of the place, and therefore will serve for all the British dominions; whereas the table of "sunrise" and "sunset" can be true only for the particular latitude of the place for which it is calculated, and can be of little, if any practical use;-at least, a general table for 
any year in the miscellaneous matter after the calendar would be quite as useful as the two columns now occupying part of each monthly space: for many reasons this supplementary table would be better, as it might be given for different latitudes, instead of being confined to one latitude. Is it probable that one person in ten thousand of all the inhabitants of London ever observe the rising sun? or would without considerable inconvenience be able so to do if inclined?

Every astronomer knows that the time of the sun's rising is influenced by many circumstances; such as the elevation of the horizon, the density and temperature of the atmosphere, and upon the latitude of the place. It might be asked, what part of the sun's dise is to be the index of its rising or setting? In a popular view, the first and last appearance of the sun would be considered the time to be observed; whereas I presume it is intended by the tables to give the time of the centre passing the sensible horizon, which differs considerably from the first and last appearance. If any person should rely upon setting their watch or clock to true time by the use of the tables published in the British Almanac, they would be deceived; whereas if they gave, like other almanacs, the sun's declination for each day, any person with a little knowledge of astronomy would be able to obtain his time by an observed altitude of the sun, at any time of the day.

If room is wanted, it might be obtained by removing much of the present contents of the first page of the month to the Supplement.

The places of the planets might also be given in a more useful form than in the vague and general manner now done at the head of the first page.

'The constellations in which the planets are to be found, occupy a portion of each monthly department. We might inquire the use of this vague information. Will any of the readers of the British Almanac be able to see either Mercury or Uranus from such a notice? Whereas if the right ascension and declination of the planets were given four or five times in the month, any person might be able to find them at proper seasons.

Want of room cannot properly be urged as a reason for the omission of useful matter; as many things are given in the calendar part of the almanac which would be quite as well in the Supplement, or in the Companion.

I would not be understood to assert that the planet Mercury cannot be seen with the naked eye, although it is an object seldom seen, in consequence of its proximity to the sun; yet there are generally a few days in the year when this planet may be easily seen; and it would be no discredit to the Bri- 
$32 \mathrm{Mr}$. W. Sturgeon on the Theory of Magnetic Electricity.

tish Almanac to point out those days, and the position in which it will be visible.

Dec, 14, 1832 .

VIII. On the Theory of Magnetic Electricity. By Mr. WILLIAM Stungeon, Member of the British Association for the P'romotion of Science : Lecturer at the Hon. East India Company's Military Academy, Addiscombe, \&c. \&c. *

[With Figures : Plate I.]

THE original plan which I had prescribed to myself for 1 the publication of my investigations on the distribution of magnetic polarity in metallic bodies, was that of first describing all those experiments which appeared to me to be the most interesting, with such explanatory remarks and practical rules for their exhibition as were necessary to their being properly and easily understood ; and afterwards to offer such theoretical inferences, with observations, as naturally presented themselves to my mind whilst contemplating the curious and novel phænomena which these inquiries elicited: and in order that the arrangement might be the more regular, uniform, and intelligible, I placed the experiments on iron in the earliest part of the detail. According to that plan, there would have been another communication previous to that which $I$ am now writing, which would have continued, and perhaps completed the detail of my former original experiments. Since sending my last communication to the press $t$, however, I have had an opportunity of perusing a paper containing the detail of the more recent experiments of Mr. Faraday, published in the Philosophical Transactions for the present year; and finding that several of the experiments there detailed, although performed with somewhat different arrangements of apparatus, are intimately connected with those of mine already published, and consequently with those also which I have not yet described, I have been induced to deviate from my original plan, and to offer more early in the series than I had intended, those theoretical elements of this new branch of physics, of which all the rules hitherto advanced for the exhibition of the phænomena, however important they may appear in a practical point of view, are but the mere consequent subordinate results.

Before proceeding further, however, with the principal object of this communication, I must beg permission to observe, that notwithstanding the title under which I have hitherto published my investigations on this subject is perfectly unobjectionable, and also sufficiently comprehensive and explanatory for all

* Communicated by the Author.

$\uparrow$ Phil. Mag. and Journ. of Science, vol. i. p. 31. 